\title{
OBSERVAÇÕES SOBRE A FILOSOFIA DA MATEMÁTICA DE LUDWIG WITTGENSTEIN
}

\author{
Gustavo Augusto Fonseca Silva ${ }^{1}$ \\ Universidade Federal de Minas Gerais (UFMG) \\ (D) http://orcid.org/0000-0001-7427-4504
}

RESUMO:

No ensaio "Wittgenstein on mathematics", publicado no Oxford Handbook of Wittgenstein, Michael Potter procura não apenas analisar por que a filosofia da matemática de Wittgenstein é tão controvertida entre filósofos e matemáticos como justificar essa situação. Com esse intuito, Potter enfatiza o caráter inacabado das reflexões de Wittgenstein sobre a matemática. Neste artigo, tem-se por objetivo explicitar algumas inconsistências e contradições no pensamento matemático de Wittgenstein que ratificam as críticas que esse autor vem recebendo há décadas, mas que não tiveram a mesma atenção dos especialistas que os comentários de Wittgenstein sobre os teoremas da incompletude de Kurt Gödel e suas discussões com Alan Turing sobre os fundamentos da matemática.

PALAVRAS-CHAVE: Ludwig Wittgenstein; Filosofia da matemática; Michael Potter.

\section{REMARKS ON LUDWIG WITTGENSTEIN'S PHILOSOPHY OF MATHEMATICS}

\begin{abstract}
:
In The Oxford Handbook of Wittgenstein, Michael Potter's essay 'Wittgenstein on mathematics' offers not only an analysis on why Wittgenstein's philosophy of mathematics is so controversial among philosophers and mathematicians but also justifies such controversy. For that purpose, Potter emphasizes that Wittgenstein's discussions on math are unfinished. This article sheds light on some inconsistencies and contradictions pertaining Wittgenstein's mathematic thoughts which, although reinforcing the decade-long criticism on the author, did not interest scholars as much as Wittgenstein's comments on Kurt Gödel's incompleteness theorems and his dialogues with Alan Turing on the foundations of mathematics.
\end{abstract}

KEYWORDS: Ludwig Wittgenstein; Philosophy of mathematics; Michael Potter.

1 Doutorando em Linguística Teórica e Descritiva pela Universidade Federal de Minas Gerais (UFMG), Minas Gerais - Brasil. E-mail: fonsecaugusto@hotmail.com

SILVA, Gustavo Augusto Fonseca. Observações sobre a filosofia da matemática de Ludwig Wittgenstein. Griot : Revista de Filosofia, Amargosa/Bahia, v.17, n.1, p.97-113, junho/2018. 


\section{Introdução}

Nenhum aspecto da obra de Ludwig Wittgenstein é mais controvertido do que a sua filosofia da matemática. Sinal maior disso é o fato de que mesmo wittgensteinianos eminentes como Merrill B. Hintikka e Jaakko Hintikka preferem deixar de lado suas reflexões sobre a matemática ao analisar o seu legado (HINTIKKA \& HINTIKKA, 1994, p. 51). "Não estamos convencidos [...] de que a filosofia da matemática de Wittgenstein tenha a mesma profundidade que a sua filosofia da linguagem ou a sua filosofia da psicologia", confessaram Hintikka e Hintikka (ibid., p. 14). Os editores do Oxford Handbook of Wittgenstein, Oskari Kuusela e Marie McGinn, por sua vez, estando obviamente cientes da avaliação negativa que se faz da filosofia da matemática de Wittgenstein desde a publicação póstuma das Observações sobre os fundamentos da matemática em 1956, admitiram na introdução do livro: "A maioria da filosofia analítica dominante ainda parece muito escandalizada pela filosofia da matemática de Wittgenstein para considerá-la muito

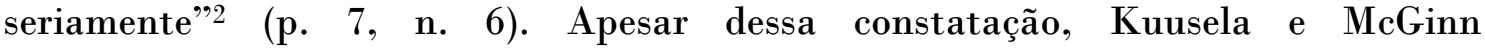
justificadamente dedicaram uma das sete partes da coletânea à lógica e à filosofia da matemática de Wittgenstein. No entanto, dos oito ensaios dessa seção, apenas um enfrenta o desafio de tentar explicar por que as ideias de Wittgenstein sobre a matemática são tão depreciadas: "Wittgenstein on mathematics", de Michael Potter.

Logo na abertura de seu texto, Potter reconhece, de maneira um tanto amena, que a literatura secundária sobre a filosofia da matemática de Wittgenstein é "peculiarmente inconclusiva" (p. 122) e que Wittgenstein não teve a mesma influência na filosofia da matemática contemporânea que teve na filosofia da linguagem e na filosofia da mente. Diante desses fatos, Potter se propõe a tarefa de ajudar a entender por que os pontos de vista de Wittgenstein sobre a matemática são tão controversos. Com esse intuito, Potter perpassa brevemente alguns tópicos da filosofia da matemática wittgensteiniana, com destaque à sua análise da sugestão feita por Wittgenstein de que o significado de uma generalização aritmética é a sua prova. Na opinião de Potter (ibid., p. 139), essa doutrina do significado como prova dominou o pensamento de Wittgenstein sobre a matemática de tal forma que, quando ele começou a duvidar de sua validade, em fins dos anos 1930, percebeu que os danos à sua concepção da matemática não poderiam ser facilmente remediados. Como consequência, observa Potter, toda a longa seção sobre a filosofia da matemática que integraria as Investigações filosóficas acabou excluída da obra. Além disso, sem ter conseguido reformular suas ideias sobre a matemática dando-lhes uma perspectiva coerente, Wittgenstein deixou apenas anotações incompletas nessa área, enfatiza Potter.

Apesar de a filosofia da matemática de Wittgenstein ser indiscutivelmente fragmentária e em vários pontos inconclusiva, isso por si só não ameniza suas inconsistências e contradições, como parece crer Potter, muito menos desculpa verdadeiros absurdos defendidos por Wittgenstein nesse campo filosófico. Os "espantosamente primitivos" (MONK, 1995, p. 270) comentários de Wittgenstein

${ }^{2}$ As traduções das citações de obras não publicadas em português foram feitas pelo autor.

SILVA, Gustavo Augusto Fonseca. Observações sobre a filosofia da matemática de Ludwig Wittgenstein. Griot : Revista de Filosofia, Amargosa/Bahia, v.17, n.1, p.97-113, junho/2018. 
sobre os teoremas da incompletude de Kurt Gödel, bem como a sua tentativa de descartá-los como meros "truques lógicos" (WITTGENSTEIN, 1987, I, apêndice III, § 19), são exemplos óbvios desses absurdos que não são atenuados levando-se em conta o caráter inacabado da filosofia da matemática de Wittgenstein. Até porque, como bem ponderou Monk (1995, p. 289), nenhuma das obras do segundo Wittgenstein pode ser considerada "acabada e definitiva", já que foram organizadas e publicadas postumamente por seus testamenteiros literários. Além do mais, o simples fato de Wittgenstein não ter conseguido finalizar seu trabalho em matemática não o exime da responsabilidade pelo que ele escreveu sobre o tema ou disse a seu respeito em seus cursos ministrados em Cambridge nos anos 1930 e 1940. A começar pelas posições que ele defendeu no famoso curso de 1939, escandalizantes a ponto de levar o matemático Alan Turing a abandonar aquelas aulas (MONK, 1995, p. 376).

Tanto os comentários de Wittgenstein sobre os teoremas da incompletude, que o próprio Gödel afirmou serem "uma interpretação errônea, totalmente trivial e desinteressante" (GOLDESTEIN, 2008, p. 100), quanto suas discussões com Turing sobre os fundamentos da matemática já forneceriam material suficiente para mostrar por que a filosofia da matemática wittgensteiniana é tão criticada - muitas vezes, de maneira enfática e mesmo irritada, como o fez o lógico e matemático Georg Kreisel, um ex-aluno de Wittgenstein, que declarou em resenha das Observações sobre os fundamentos da matemática: "Os pontos de vista de Wittgenstein sobre lógica matemática não têm muito valor, pois ele conhecia muito pouco do assunto e esse pouco restringia-se às mercadorias da linhagem Frege-Russell" (MONK, 1995, p. 441). No entanto, dada a imensa bibliografia existente a respeito dos embates entre Wittgenstein e Gödel e a respeito dos embates entre Wittgenstein e Turing, neste artigo serão analisados outros tópicos do pensamento matemático wittgensteiniano, geralmente negligenciados nesses estudos. $\mathrm{O}$ objetivo ao fazê-lo é salientar por que a maioria da filosofia analítica dominante tem razão em estar muito escandalizada pela filosofia da matemática de Wittgenstein para considerá-la muito seriamente.

A matemática como história natural do domínio do número e como uma coleção de regras

Assim como compara a linguagem a um jogo em sua segunda filosofia (e.g. WITTGENSTEIN, 1987, VI, § 43; 1999, § 199; 2001, p. 48), Wittgenstein recorrentemente compara a matemática a um jogo em suas aulas e em seus textos dos anos 1930 e 1940. Na Gramática filosófica, por exemplo, Wittgenstein perguntase: "O que estamos tirando da matemática quando dizemos que ela é apenas um jogo (ou: é um jogo)?" (p. 227). E responde logo adiante: "Se você quer dizer que a matemática é jogada como o xadrez ou a paciência e o objetivo é vencer ou sair, isso está evidentemente incorreto" (ibid.). Conforme Wittgenstein (ibid., p. 229), "chamar a aritmética de jogo não é mais nem menos errado que chamar o mover peças de xadrez, segundo regras de xadrez, de jogo, pois isso também poderia ser um cálculo". Assim, para Wittgenstein, a matemática é apenas um jogo e, como tal, seguem-se as regras "cegamente" (WITTGENSTEIN, 1999, § 219) e o jogo é jogado. Ao afirmá-lo, no entanto, Wittgenstein aparentemente desconsiderou que um jogo

SILVA, Gustavo Augusto Fonseca. Observações sobre a filosofia da matemática de Ludwig Wittgenstein. Griot : Revista de Filosofia, Amargosa/Bahia, v.17, n.1, p.97-113, junho/2018. 
pode ter qualquer regra, estabelecida arbitrariamente; a matemática não. Seria possível, por exemplo, dobrar o número de peças de xadrez ou alterar o movimento delas (uma torre poderia saltar peças, por exemplo) e assim teríamos outro jogo que não o xadrez, porque "se você segue outras regras que não as do xadrez você está jogando outro jogo" (WITTGENSTEIN, 2003, p. 139). Mas não é possível estabelecer arbitrariamente outras regras matemáticas. Afinal, "você não pode arredondar a matemática, não mais do que pode dizer 'vamos arredondar as quatro cores primárias para oito ou dez' ou 'vamos arredondar para dez os oito tons de uma oitava" (ibid., p. 289). Atento a esse fato e ciente das dificuldades que ele traz para a analogia entre a matemática e um jogo, Wittgenstein comentou com seus alunos em 1939:

Foi dito muito frequentemente que a matemática é um jogo, a ser comparado com o xadrez. Em certo sentido isso é obviamente falso - não é um jogo no sentido comum. Em um sentido é obviamente verdadeiro - há certa similaridade. A coisa a fazer não é tomar partido, mas investigar. Algumas vezes, é útil comparar a matemática a um jogo e algumas vezes é enganador.

Há um argumento usado muitas vezes contra a ideia de que a matemática é um jogo: "Tudo bem - ela é comparável ao xadrez. Movimentos no tabuleiro podem ser comparados com transformações de expressões matemáticas. Mas no xadrez nós temos de distinguir entre (1) jogos jogados por pessoas diferentes; (2) a teoria do jogo". ${ }^{3}$

Se você compara a matemática a um jogo, uma razão é que você quer mostrar que em certo sentido ela é arbitrária - o que certamente é enganador e um caminho muito perigoso. - Agora eu disse coisas que podem ser interpretadas deste jeito: "Você poderia fazê-la de outra maneira", etc. - Mas se você diz que as regras do xadrez são arbitrárias, seus oponentes dirão que a teoria do xadrez não é arbitrária. Se você provar que você não pode dar mate com dois cavalos, isso é um fato, uma verdade - e não é arbitrária. - Então, se você tivesse uma parte da matemática que fosse um jogo, então de qualquer modo haveria uma outra parte - a teoria do jogo - que não seria um jogo e não seria arbitrária (WITTGENSTEIN, 1989, p. 142-143).

Sem dúvidas, algumas vezes, é útil comparar a matemática a um jogo, como o fizeram Wittgenstein e outros tantos antes dele, entre os quais o matemático formalista David Hilbert, que afirmou que "a matemática é um jogo, que segue certas regras simples, com marcas sem sentido no papel" (GOLDESTEIN, 2008, p. 115). No entanto, não parece haver utilidade alguma em escrever, de um lado, que você não pode arredondar a matemática e, de outro, dizer que em Marte talvez haja outra aritmética: "Pelo que eu saiba", disse Wittgenstein aos seus alunos em 1939, "os marcianos talvez ensinem aos filhos o Principia e então as crianças multiplicam. Mas eles poderiam manter o Principia e dizer que 20 × 30 não é 600, mas 601, e ter de modo geral uma aritmética bem diferente" (WITTGENSTEIN, 1989, p. 261). Além disso, no mesmo período em que cogitava com seus alunos a possibilidade de uma aritmética marciana, Wittgenstein contraditoriamente observou:

${ }^{3}$ Cf. Frege, Grundgesetze der Arithmetik, Vol. II, § 93, pp. 101-102 (nota da editora Cora Diamond).

SILVA, Gustavo Augusto Fonseca. Observações sobre a filosofia da matemática de Ludwig Wittgenstein. Griot : Revista de Filosofia, Amargosa/Bahia, v.17, n.1, p.97-113, junho/2018. 
A proposição matemática tem a dignidade de uma regra. Isto é verdadeiro porque a matemática é lógica: move-se nas regras de nossa linguagem. $\mathrm{E}$ isso é o que lhe proporciona sua peculiar solidez, seu lugar privilegiado e inexpugnável. (A matemática depositada entre as normas originais.) (WITTGENSTEIN, 1987, IV, § 13)

Poucos anos mais tarde, em 1942, Wittgenstein reiteraria o lugar privilegiado e inexpugnável que a matemática ocupa ao afirmar: "Poderia dizer-se: que leis maravilhosas imprimiu o Criador nos números!" (WITTGENSTEIN, 1992a, p. 67). Na mesma época, Wittgenstein escreveria ainda: "Eu gostaria de poder expor como é que às vezes a matemática nos parece como história natural do domínio do número, e, às vezes, como uma coleção de regras" (WITTGENSTEIN, 1987, IV, § 13). E eu gostaria de poder expor como Wittgenstein é frequentemente contraditório em sua filosofia da matemática. Um problema do qual o próprio Wittgenstein estava ciente, como confessou a Chadbourne Gilpatrick já no fim da vida, ao responder-lhe quando aconselhado a publicar seus textos com uma verba que receberia: "Mas, veja, eu escrevo uma frase, e depois outra, que diz precisamente o contrário. E qual há de ser mantida?" (BOUWSMA, 2005, p. 121).

\section{Entre a verdade e a possibilidade}

Ainda às voltas com a analogia entre a matemática e um jogo, Wittgenstein escreveu nas Observações filosóficas (p. 120):

Uma equação é uma regra da sintaxe.

Isso não explica por que não podemos ter na matemática perguntas que são, em princípio, irrespondíveis? Pois regras da sintaxe que não podem ser compreendidas não têm absolutamente nenhuma utilidade. Explica ainda por que um infinito que transcende os nossos poderes de compreensão não pode entrar nessas regras. E também torna compreensíveis as tentativas dos formalistas de ver a matemática como um jogo com signos.

Tendo em vista as tentativas dos formalistas de ver a matemática como um jogo com signos, Wittgenstein ponderou com os filósofos do Círculo de Viena Friedrich Waismann e Moritz Schlick:

\footnotetext{
A verdade sobre o formalismo é que permite tomar toda a sintaxe como um sistema de regras de jogo. Penso que Weyl poderia haver dito isso quando afirma que o formalismo toma os axiomas da matemática como regras de xadrez. Eu, portanto, adicionaria: não apenas são arbitrários os axiomas da matemática, mas toda a sintaxe (WAISMANN, 1973, p. 91).
}

Mas os axiomas da matemática, bem como toda a sintaxe, são realmente arbitrários, como o são as regras de um jogo qualquer? "A sintaxe não tem fundamentos; por isso é arbitrária", afirmou Wittgenstein a Waismann e a Schlick (ibid., p. 92). "Independentemente de seu emprego e considerada em si, é um jogo; exatamente como o jogo de xadrez." Mais adiante, Wittgenstein completou: "À configuração do jogo corresponde uma regra da sintaxe. [...] A sintaxe não pode ser

SILVA, Gustavo Augusto Fonseca. Observações sobre a filosofia da matemática de Ludwig Wittgenstein. Griot : Revista de Filosofia, Amargosa/Bahia, v.17, n.1, p.97-113, junho/2018. 
justificada" (ibid., p. 112). E exemplificou: "Aqui está um círculo. Seu comprimento é $3 \mathrm{~cm}$ e sua largura é $2 \mathrm{~cm}$.' 'Ora! Mas o que você quer dizer então com círculo?"” (MONK, 1995, p. 261). "Em outras palavras", esclarece Monk (ibid.), "a possibilidade de um círculo mais comprido do que largo é excluída por aquilo que queremos dizer com a palavra 'círculo'. Essas regras são estipuladas pela sintaxe, ou, como Wittgenstein às vezes prefere, pela 'gramática' da nossa linguagem, que neste caso estabelece um 'vínculo interno' entre alguma coisa ser um círculo e ela ter apenas um raio." Ou seja, "a sintaxe dos termos geométricos proíbe, a priori, a existência de tais círculos, assim como a sintaxe das cores exclui a possibilidade de uma coisa ser ao mesmo tempo vermelha e azul" (ibid.). Portanto, se os axiomas da matemática fossem de fato arbitrários, a "sintaxe dos termos geométricos" poderia ser alterada arbitrariamente e incluir, por exemplo, a existência de um círculo com 3 cm de comprimento e $2 \mathrm{~cm}$ de largura. Mas é evidente que a "sintaxe dos termos geométricos" não é estabelecida arbitrariamente - incluindo, é claro, a sintaxe dos termos das geometrias não euclidianas. Por isso, não surpreende que Wittgenstein, por exemplo, tenha afirmado no $§ 208$ das Investigações filosóficas que "o fato de não podermos escrever todas as casas decimais de $\pi$ não é uma insuficiência humana". Surpreende, no entanto, que Wittgenstein, por um lado, tenha dito a Waismann e a Schlick que a sintaxe não tem fundamentos e por isso é arbitrária, sendo um jogo, independentemente de seu emprego e considerada em si, exatamente como o jogo de xadrez; e por outro tenha escrito:

Pensa na frase: “O vermelho não é uma cor mista" e na sua função.

O jogo de linguagem é caracterizado pelo que podemos e não podemos fazer (WITTGENSTEIN, 1992b, § 345).

"Não existe o verde avermelhado" é análogo às frases que usamos como axiomas na matemática (ibid., $\S 346)$.

Em uma aula do início dos anos 1930, Wittgenstein esclareceu a seus alunos: “(A gramática) nos deixa fazer certas coisas com a linguagem e não outras; estabelece o grau de liberdade" (MONK, 1995, p. 266). "O octaedro de cores é, neste sentido, um exemplo de gramática", explica Monk (ibid.), "pois estabelece que, embora possamos falar de um azul esverdeado, não podemos falar de um vermelho esverdeado. Refere-se, portanto, à verdade e não à possibilidade. Neste mesmo sentido, a geometria é também parte da gramática." E neste mesmo sentido fica claro que não faz sentido afirmar que a sintaxe, a gramática, não tem fundamentos e por isso é arbitrária, sendo um jogo, independentemente de seu emprego e considerada em si, exatamente como o jogo de xadrez. Afinal, se a sintaxe, a gramática, fosse arbitrária, como um jogo qualquer, poderíamos estabelecer novas regras arbitrariamente e falar, por exemplo, de um vermelho esverdeado ou de um verde avermelhado, assim como poderíamos estabelecer novos axiomas na matemática e dizer que 20 x 30 não é 600, mas 601, e ter de modo geral uma aritmética bem diferente. Mas é claro que isso é impossível.

Sem ter se decidido, no entanto, sobre a questão relativa à arbitrariedade da sintaxe, Wittgenstein ponderaria ainda:

SILVA, Gustavo Augusto Fonseca. Observações sobre a filosofia da matemática de Ludwig Wittgenstein. Griot : Revista de Filosofia, Amargosa/Bahia, v.17, n.1, p.97-113, junho/2018. 
Temos um sistema de cores, tal como temos um sistema de números. Residirão os sistemas na nossa natureza ou na natureza das coisas? Como devemos dizer? - Não na natureza dos números ou das cores (WITTGENSTEIN, 1992b, § 357).

Existe então algo de arbitrário neste sistema? Sim e não. É aparentado com o que é arbitrário e com o que é não arbitrário (ibid., § 358).

Existe realmente algo de arbitrário neste sistema, como existe em um jogo qualquer? Se sim, como explicaríamos por que ainda não foi criado um sistema de cores que estabelece que possamos falar tanto de um azul esverdeado quanto de um vermelho esverdeado? E como explicaríamos por que ainda não foi criado um sistema de números que estabelece, por exemplo, que possamos dizer que 20 x 30 não é 600 , mas 601? Uma possibilidade que Wittgenstein chega a cogitar em outra aula no início dos anos 1930: "Se toda vez que contássemos 40 mais 20 nós obtivéssemos 61, então nossa aritmética seria estranha. Nós poderíamos construir uma aritmética na qual isso fosse verdade, e isso não é dizer que 61 é o mesmo que 60 " (WITTGENSTEIN, 2001, p. 84). Mas deveríamos ficar surpresos com o fato de Wittgenstein não ter construído essa aritmética? E deveríamos ficar surpresos com o fato de Wittgenstein ter dito anos mais tarde precisamente o contrário do que havia dito a seus alunos? Nas Observações sobre os fundamentos da matemática, por exemplo, Wittgenstein afirma:

\footnotetext{
Mas se digo agora: "Veja, assim resulta 5 de $3+2$ ", e coloco ao mesmo tempo sobre a mesa 3 maçãs e logo outras 2 , então o que quero dizer é, por exemplo: 3 maçãs e 2 maçãs dão 5 maçãs, se não desaparece nem se adiciona alguma. - Ou também poderia dizer-se a alguém: Se (como eu agora) você coloca sobre a mesa 3 maçãs e logo outras 2 , sucede quase sempre o que você vê agora, e há aqui 5 maçãs.

Quero mostrar-lhe, por exemplo, que 3 maçãs e 2 maçãs não dão 5 maçãs assim como poderiam dar 6 maçãs (se aparecesse mais uma de repente, por exemplo). Isso é propriamente uma explicação, uma definição da operação da soma $(\mathrm{VI}, \S 9)$.
}

E quero mostrar-lhe que 40 maçãs e 20 maçãs não dão 60 maçãs assim como poderiam dar 61 maçãs (se aparecesse mais uma de repente, por exemplo). Nós não poderíamos construir uma aritmética na qual 40 maçãs e 20 maçãs dessem 61 maçãs. Isso é propriamente uma explicação, uma definição da operação da soma. Além disso, conforme ensinou Wittgenstein a seus alunos em 1939, "nós não deveríamos nunca deixar nada provar que estamos errados em dizer que $12 \times 12=144$. Porque isso é o que nós chamamos multiplicação correta" (WITTGENSTEIN, 1989, p. 291). E nós não deveríamos nunca deixar nada provar que estamos errados em dizer que $20 \times 30=600$. Porque isso igualmente é o que nós chamamos multiplicação correta.

\section{Entre a descoberta e a invenção}

Em outra aula de 1939, Wittgenstein disse ainda aos alunos: "Tentarei repetidas vezes mostrar que o que se chama descoberta matemática deveria ser chamado invenção matemática" (WITTGENSTEIN, 1989, p. 22). Anos antes, no curso "Filosofia para matemáticos", ministrado entre 1932 e 1933, Wittgenstein já

SILVA, Gustavo Augusto Fonseca. Observações sobre a filosofia da matemática de Ludwig Wittgenstein. Griot : Revista de Filosofia, Amargosa/Bahia, v.17, n.1, p.97-113, junho/2018. 
defendia essa posição. Durante esse curso, segundo Monk (ibid., p. 297), Wittgenstein lia trechos do livro didático de G. H. Hardy $A$ course of pure mathematics para exemplificar as "névoas filosóficas" que, em sua opinião, perpassavam toda a matemática. Essas "névoas", conforme Wittgenstein, surgiam devido a dois pressupostos da matemática largamente aceitos pelos matemáticos: o primeiro o de que a matemática repousa sobre os fundamentos lógicos conferidos a ela por pensadores como Cantor, Frege e Russell; o segundo o de que fazer matemática é descobrir fatos objetivamente verdadeiros. Os próprios Frege e Russell, que tanto influenciaram o jovem Wittgenstein, como se sabe defendiam a concepção de que fazer matemática é descobrir fatos objetivamente verdadeiros. No $§ 96$ dos Fundamentos da aritmética, por exemplo, Frege expressa essa concepção categoricamente: "[...] o matemático nada pode criar arbitrariamente, não mais do que o geógrafo; também ele apenas pode descobrir o que há e nomeá-lo". Russell, por sua vez, defendeu a verdade objetiva da matemática, por exemplo, na coletânea Misticismo e lógica, na qual escreveu que "não apenas é a matemática independente de nós e de nossos pensamentos, mas num outro sentido nós e todo o universo das coisas existentes somos independentes da matemática" (p. 78). Já Hardy apresentou a mesma opinião sobre a verdade objetiva da matemática, por exemplo, na conferência "Mathematical proof", publicada na Mind em 1929:

Nenhuma filosofia pode ser aceitável para um matemático se não admitir, de uma ou outra maneira, a validade imutável e incondicional da verdade matemática. Os teoremas matemáticos são verdadeiros ou falsos; sua veracidade ou falsidade é absoluta e independente do que conhecemos deles. Em algum sentido, a verdade matemática é parte da realidade objetiva. [...] (As proposições matemáticas) são, em um ou outro sentido, por mais fugaz e sofisticado que esse sentido possa parecer, teoremas que concernem à realidade. [...] Não são criações de nossa mente (MONK, 1995, p. 298).

Segundo Monk (ibid.), “o tom e o conteúdo dessa conferência enfureceram Wittgenstein". Wittgenstein, no entanto, ateve-se a criticá-la com seus alunos em vez de debatê-la com Hardy ou em vez de publicar um artigo na própria Mind apresentando sua visão da matemática. Aos seus alunos, Wittgenstein afirmou:

O discurso dos matemáticos torna-se absurdo quando eles se afastam da matemática - por exemplo, quando Hardy afirma que a matemática não é uma criação da nossa mente. Ele concebe a filosofia como um ornamento, uma atmosfera, em torno das verdades tangíveis da matemática e da ciência. Estas disciplinas, de um lado, e a filosofia, de outro, são vistas respectivamente como os elementos necessários e os ornamentais de uma sala. Hardy está pensando em opiniões filosóficas. Eu concebo a filosofia como uma atividade de elucidação do pensamento (ibid.).

"Para Wittgenstein”, observa Monk (ibid.), "a própria ideia de a matemática ocupar-se da descoberta de verdades é um equívoco que surgiu com o desenvolvimento da matemática pura e com a separação entre a matemática e as ciências físicas [...]." Um equívoco do qual Wittgenstein já havia falado com Waismann e Schlick, aos quais havia afirmado que, "em gramática, não se pode

SILVA, Gustavo Augusto Fonseca. Observações sobre a filosofia da matemática de Ludwig Wittgenstein. Griot : Revista de Filosofia, Amargosa/Bahia, v.17, n.1, p.97-113, junho/2018. 
descobrir nada; não há surpresas" (WAISMANN, 1973, p. 69); que, “em gramática, não se pode descobrir nada, mas apenas esclarecer-se" (ibid., p. 70); e que, "na matemática, é tão impossível descobrir algo como na gramática" (ibid., p. 56). Anos mais tarde, Wittgenstein reiteraria essa concepção da matemática ao declarar: "O matemático é um inventor, não um descobridor" (1987, I, § 168). Uma questão, no entanto, imediatamente surge diante dessa perspectiva do matemático como um inventor: se o matemático é um inventor, não um descobridor, por que você não pode arredondar a matemática, como admitiu o próprio Wittgenstein? Além disso, se o que se chama descoberta matemática deveria ser chamado invenção matemática, por que não há diferentes matemáticas, inventadas arbitrariamente com diferentes axiomas? Quanto a isso,

a dificuldade parece repousar em conciliar a visão de que a matemática é uma invenção humana com ela aparentemente nos forçar a aceitar certas conclusões, que em muitos casos nós temos de nos esforçar para descobrir. Então, nós estamos livres para definir um número primo como aquele que é divisível apenas por 1 ou por si mesmo, mas, tendo introduzido esse conceito, nós não controlamos sua aplicação; nós temos de descobrir quais números são primos (AYER, 1985, p. 64).

Assim, se o que se chama descoberta matemática deveria ser chamado invenção matemática, por que os matemáticos não simplesmente controlaram a aplicação do conceito de número primo, em vez de se esforçar para descobri-los? Mas mais importante: por que deveríamos ficar surpresos com o fato de Wittgenstein ter dito no mesmo curso de 1939 precisamente o contrário do que havia dito antes? "Nós não estamos desprezando os matemáticos; nós só estamos traçando uma importante distinção - entre descobrir alguma coisa e inventar alguma coisa. Mas os matemáticos fazem as mais importantes descobertas" (1989, p. 67), disse Wittgenstein a seus alunos.

\section{Ataque quixotesco à matemática pura}

É possível afirmar que Wittgenstein se interessava tanto pela comparação entre a matemática e um jogo devido à sua convicção de que a matemática não é uma ciência. No entanto, conforme Monk (1995, p. 295-296), Wittgenstein sabia que, por contrariar a visão predominante de que a matemática é uma ciência, com fatos objetivamente verdadeiros a descobrir, ele não chegaria efetivamente a influenciar o trabalho dos matemáticos. E Wittgenstein - com seu "ataque quixotesco" à matemática pura, como o denominou Monk (ibid., p. 297) - de fato não influenciou efetivamente o trabalho dos matemáticos. Para Wittgenstein, explica Monk (ibid., p. 278), "enquanto pudermos usar os símbolos matemáticos corretamente - enquanto pudermos aplicar as regras -, nenhuma "teoria' da matemática se faz necessária". Assim, "uma justificação definitiva e fundamental dessas regras não é possível nem desejável", o que "significa que todo o debate sobre os 'fundamentos' da matemática parte de um equívoco". Mas foi justamente esse debate que atraiu Wittgenstein para a filosofia. Exatamente por isso, na opinião de Monk (ibid., p. 279), Wittgenstein continuou se dedicando a esse ramo da filosofia, apesar de suas convicções

SILVA, Gustavo Augusto Fonseca. Observações sobre a filosofia da matemática de Ludwig Wittgenstein. Griot : Revista de 
spenglerianas da superioridade da música e das artes sobre a matemática e as ciências.

Ainda de acordo com Monk (ibid.), tendo abandonado o logicismo, Wittgenstein passou a declarar fúteis as contradições na lógica de Frege descobertas por Russell, cuja resolução ele antes acreditava ser a tarefa fundamental da filosofia. Mais: Wittgenstein passou a declarar fúteis as contradições de modo geral, convencido de que o problema não são as contradições, mas a visão imperfeita que as faz parecer dilemas importantes e interessantes: "Cria-se um jogo e descobre-se que duas regras podem, em certos casos, contradizer-se mutuamente. E daí? 'O que fazemos num caso assim? Muito simples - introduzimos uma nova regra e o conflito fica resolvido" (ibid.). Mas por que deveríamos ficar surpresos com o fato de Wittgenstein não ter resolvido o paradoxo de Russell simplesmente introduzindo uma nova regra? E por que deveríamos ficar surpresos com o fato de Wittgenstein, que vaticinava que "os problemas filosóficos nascem quando a linguagem entra em férias" (1999, § 38), ter atribuído ao logicismo uma má interpretação da linguagem? Nas Observações sobre os fundamentos da matemática ( $\mathrm{V}, \S 48)$, por exemplo, Wittgenstein afirma:

A 'lógica matemática' deformou totalmente o pensamento de matemáticos e filósofos, já que, como análise das estruturas dos atos, instaurou uma interpretação superficial das formas de nossa linguagem corrente. $O$ único que fez a este respeito, certamente, é ter continuado edificando sobre a lógica aristotélica.

Na Gramática filosófica (p. 207), Wittgenstein exemplifica de forma clara como a lógica matemática supostamente deformou totalmente o pensamento de matemáticos e filósofos por ter supostamente instaurado uma interpretação superficial das formas de nossa linguagem corrente:

A real dificuldade encontra-se no conceito de " $(\exists n)$ " e, em geral, de " $(\exists x)$ ". A fonte original dessa notação é a expressão de nossa linguagem de palavras: "Existe um... com tais e tais propriedades". E, no caso, o que substitui os pontos é algo como "livro da minha biblioteca" ou "coisa (corpo) nesta sala", "palavra nesta carta" etc. Pensamos em objetos pelos quais podemos passar um após o outro. Como tantas vezes acontece, um processo de sublimação transformou essa forma em "há um objeto tal que..." e, aqui também, as pessoas imaginaram originalmente os objetos do mundo como iguais a "objetos" na sala (mesas, cadeiras, livros etc.), embora esteja claro que, em muitos casos, a gramática dessa " $(\exists x)$ etc." não seja a mesma que a gramática do caso primitivo que serve como paradigma. A discrepância entre a imagem original e aquela à qual a notação agora é aplicada torna-se particularmente palpável quando uma proposição como "há dois círculos neste quadrado" é traduzida como "não há nenhum objeto que tenha a propriedade de ser um círculo neste quadrado". A proposição "há apenas duas coisas que são círculos neste quadrado" (interpretada sobre o modelo da proposição "há apenas dois homens que escalaram esta montanha") parece louca, com boa razão. Isto é, não se ganha nada ao forçar a proposição "há dois círculos neste quadrado" nessa forma; só ajuda a ocultar que não esclarecemos a gramática da proposição. Mas, ao mesmo tempo, a notação russelliana, no caso, nos dá uma aparência de exatidão que faz as pessoas acreditarem que

SILVA, Gustavo Augusto Fonseca. Observações sobre a filosofia da matemática de Ludwig Wittgenstein. Griot : Revista de Filosofia, Amargosa/Bahia, v.17, n.1, p.97-113, junho/2018. 
os problemas são resolvidos colocando a proposição em uma forma russelliana. [...]

"Uma das quatro pernas desta mesa não se segura", "Há ingleses com cabelos negros", "Há uma mancha nesta parede", "Os dois vasos têm o mesmo peso", "Há o mesmo número de palavras em cada uma das duas páginas". Em todos esses casos, na notação russelliana, o "[ $\exists$...]..." é usado e, cada vez, com uma gramática diferente. O que quero dizer é que se ganha pouca coisa traduzindo tal sentença da linguagem das palavras para a notação russelliana.

E o que quero dizer é que o filósofo G. F. Warnock - um dos "adeptos de WII", como Russell (1960, p. 194) denominava os discípulos do segundo Wittgenstein -, fez críticas semelhantes à notação russelliana antes da publicação da Gramática filosófica, as quais foram devidamente refutadas por Russell (ibid., p. 206213) com o auxílio de uma fábula sobre os "isidianos". Segundo Russell, os isidianos eram um povo cuja linguagem continha as palavras "barrigudinho", "truta", "perca" e "lúcio", mas não a palavra "peixe". Certo dia, um grupo de isidianos pescou o que chamamos de salmão. Sem terem um nome próprio para aquele animal, eles discutiram furiosamente sobre como deveriam chamá-lo. Um desconhecido que os viu naquela situação disse-lhes que sua tribo tinha uma palavra que se aplicava igualmente a barrigudinhos, trutas, percas, lúcios e àquele animal que eles tinham pescado: "peixe". Os isidianos, no entanto, consideraram essa palavra como um pedantismo inútil. "Diz Mr. Warnock que o numeral existencial confunde coisas que a linguagem comum distingue", observa Russell ao fim da fábula. "Isso é exatamente como se os isidianos tivessem se queixado de que um homem que usa a palavra "peixe" confunde barrigudinhos com lúcios" (ibid., p. 208).

Convencido de que a notação russelliana confunde coisas que a linguagem comum distingue, Wittgenstein afirma na Gramática filosófica:

Todos os erros que foram cometidos neste capítulo da filosofia da matemática baseiam-se na confusão entre propriedades internas de uma forma (uma regra como uma entre uma lista de regras) e o que chamo de "propriedades" na vida cotidiana (o vermelho como uma propriedade deste livro). Também poderíamos dizer: as contradições e obscuridades são ocasionadas por pessoas usando uma única palavra, por exemplo, "número", para designar em uma ocasião um conjunto definido de regras e, em outro, um conjunto variável, como designar como "xadrez" em uma ocasião o jogo definido que jogamos hoje e, em outra, o substrato de um desenvolvimento histórico particular (p. 382).

Em seu curso de 1939 sobre a filosofia da matemática, Wittgenstein apresentou algumas considerações linguísticas semelhantes e por fim concluiu:

Essas discussões tiveram um ponto: mostrar a diferença essencial entre os usos de proposições matemáticas e os usos de proposições não matemáticas que parecem ser exatamente análogas com elas.

Proposições matemáticas são em primeiro lugar sentenças inglesas; não apenas sentenças inglesas, mas cada proposição matemática tem uma semelhança com algumas proposições não matemáticas. - Matemáticos, quando começam a filosofar, sempre cometem o erro de ignorar a diferença

SILVA, Gustavo Augusto Fonseca. Observações sobre a filosofia da matemática de Ludwig Wittgenstein. Griot : Revista de Filosofia, Amargosa/Bahia, v.17, n.1, p.97-113, junho/2018. 
de função entre proposições matemáticas e proposições não matemáticas (WITTGENSTEIN, 1989, p. 111).

Mas quais matemáticos, quando começam a filosofar, sempre cometem o erro de ignorar a diferença de função entre proposições matemáticas e proposições não matemáticas? O próprio Russell, por exemplo, jamais ignorou essa diferença. Não por acaso, logo no segundo parágrafo do apêndice $\mathrm{A}$ do livro The principles of mathematics, dedicado à filosofia de Frege, Russell afirma: "Frege é forçado, como eu, a empregar palavras comuns em sentidos técnicos que diferem mais ou menos do uso" (p. 501). Em seguida, Russell detalha essas diferenças, bem como as diferenças entre seus termos técnicos e os de Frege, sem haver confusão alguma entre propriedades internas de uma forma e o que Wittgenstein chama de "propriedades" na vida cotidiana. Assim, é necessário perguntar mais uma vez: quais matemáticos, quando começam a filosofar, sempre cometem o erro de ignorar a diferença de função entre proposições matemáticas e proposições não matemáticas? A quais matemáticos Wittgenstein se referia? "As Investigações raramente identificam os alvos de seus ataques", bem observa Hans-Johann Glock (1998, p. 223). "Alguns leitores têm, por isso, criticado Wittgenstein, afirmando que ele parece estar exorcizando concepções que ninguém jamais sustentou." Não apenas nas Investigações filosóficas, mas em toda a sua segunda filosofia, Wittgenstein raramente identifica os alvos de seus ataques e parece estar exorcizando concepções que ninguém jamais sustentou. No Livro azul, por exemplo, Wittgenstein afirma: "Quando as palavras na nossa linguagem vulgar têm, à primeira vista, gramáticas análogas, tendemos a tentar interpretá-las de modo análogo; isto é, tentamos manter a analogia a qualquer preço" (p. 30). E exemplifica mais adiante:

[...] podemos dizer de alguns matemáticos com inclinações filosóficas que eles não estão evidentemente cientes da diferença existente entre os muitos diversos usos da palavra "demonstração"; e que eles não clarificaram a diferença entre os usos da palavra "espécie", quando falam de espécies de números, espécies de demonstrações, como se a palavra "espécie" significasse aqui o mesmo que no contexto "espécies de maçãs". Ou podemos dizer que eles não têm conhecimento dos diferentes sentidos da palavra "descoberta", quando num caso falamos da descoberta da construção do pentágono e, num outro caso, da descoberta do Polo Sul (p. $62)$.

E podemos dizer de Wittgenstein que ele, sem identificar os alvos de seus ataques, parece estar exorcizando confusões que nenhum matemático jamais fez, acreditando que eles não estavam cientes da diferença existente entre os muitos diversos usos da palavra "demonstração"; e que eles não clarificaram a diferença entre os usos da palavra "espécie", quando falavam de espécies de números, espécies de demonstrações, como se a palavra "espécie" significasse aqui o mesmo que no contexto "espécies de maçãs". E ainda que eles não tinham conhecimento dos diferentes sentidos da palavra "descoberta", quando num caso falavam da descoberta da construção do pentágono e, num outro caso, da descoberta do Polo Sul. Esta última certamente uma observação sobre a velha analogia feita pelos matemáticos entre uma descoberta matemática e a descoberta de um continente. Uma analogia

SILVA, Gustavo Augusto Fonseca. Observações sobre a filosofia da matemática de Ludwig Wittgenstein. Griot : Revista de Filosofia, Amargosa/Bahia, v.17, n.1, p.97-113, junho/2018. 
que levou Wittgenstein a explicitar os diferentes sentidos da palavra "descoberta" e a criticar com Waismann a concepção que Frege tinha dos números: "Ele pensa que os números já estão lá de alguma maneira, de modo que a descoberta dos números imaginários é comparável, digamos, à descoberta de um continente desconhecido" (WITTGENSTEIN \& WAISMANN, 2003, p. 153). Frege realmente pensava que os números já estão lá de alguma maneira, cabendo ao matemático descobri-los, e não inventá-los, como declarou no já citado $§ 96$ dos Fundamentos da aritmética. Russell igualmente pensava que os números já estão lá de alguma maneira, cabendo ao matemático descobri-los, e não inventá-los, conforme argumentou no $\S 427$ dos Principles of mathematics: "[...] a aritmética deve ser descoberta exatamente no mesmo sentido em que Colombo descobriu as Índias Ocidentais, e nós não mais criamos os números do que ele criou os índios". Muitos séculos antes de Frege e de Russell, o platônico Santo Agostinho, que Wittgenstein tanto admirava (DRURY, 1984, p. 90), já defendia a ideia de que os números já estão lá de alguma maneira, cabendo ao matemático descobri-los, e não inventá-los, como afirmou na Doutrina cristã (II, 39, 56):

\footnotetext{
Quanto à ciência dos números, é evidente - até para todos os espíritos, inclusive os mais lentos - que ela não foi inventada pelos homens, mas apenas procurada e descoberta por eles. Pois com ela não acontece como se deu com a primeira sílaba da palavra Itália, que os antigos pronunciavam breve, mas que se tornou longa pela vontade de Virgílio. Não está no poder de ninguém, a seu bel-prazer, fazer que três vezes três sejam nove; que nove não possa formar um quadrado; que esse número contenha uma vez e meia seis; que não possa ser o duplo de um número inteiro, já que os números ímpares não se dividem por dois.

Seja, pois, que se considerem as leis numéricas em si próprias, seja que se utilizem como leis da geometria ou da música ou de outros movimentos, elas sempre têm regras imutáveis, que não foram de modo algum inventadas pelos homens, mas sim descobertas pela sagacidade de espíritos engenhosos.
}

Mas o fato de Santo Agostinho, Frege e Russell, como tantos outros filósofos e matemáticos, pensarem que a matemática é descoberta, e não inventada, evidentemente não significa que eles não tinham conhecimento dos diferentes sentidos da palavra "descoberta", quando num caso falavam de uma descoberta matemática e, num outro caso, de uma descoberta geográfica. Prova disso é que no prefácio de Introduction to mathematical thinking, livro em que a crítica de Wittgenstein e de Waismann a Frege é reproduzida (p. 241-242), Waismann recorre justamente à analogia entre uma descoberta matemática e uma descoberta geográfica - sem confusão alguma, é claro:

Procedendo de pontos de vista intuitivos, Leibniz e Newton criaram o cálculo diferencial e integral. No século 18, essas investigações se elevaram extraordinariamente, uma descoberta brilhante seguindo-se à outra na esfera da análise pura assim como no domínio de suas aplicações. Esse período da matemática foi comparado, não injustamente, com o período das grandes descobertas e dos heróis do mar. Os matemáticos daquele período tinham a sensação de estar pisando em um novo mundo

SILVA, Gustavo Augusto Fonseca. Observações sobre a filosofia da matemática de Ludwig Wittgenstein. Griot : Revista de Filosofia, Amargosa/Bahia, v.17, n.1, p.97-113, junho/2018. 
intelectual, ávidos em explorar os contornos do continente que se abria para eles da neblina.

Estando, porém, persuadido não apenas de que, quando as palavras na nossa linguagem vulgar têm, à primeira vista, gramáticas análogas, tentamos manter a analogia a qualquer preço, mas também de que "a filosofia explicita as analogias enganadoras no uso de nossa linguagem" (WITTGENSTEIN, 2005b, § 87), Wittgenstein é taxativo:

Nossa consideração é [...] gramatical. E esta consideração traz luz para o nosso problema, afastando os mal-entendidos. Mal-entendidos que concernem ao uso das palavras; provocados, entre outras coisas, por certas analogias entre as formas de expressão em diferentes domínios da nossa linguagem (WITTGENSTEIN, 1999, § 90).

Assim, uma analogia entre formas de expressão em diferentes domínios da nossa linguagem levava Wittgenstein a explicitar os diferentes sentidos de uma palavra, como o fez em uma aula no início dos anos 1930, na qual disse aos alunos:

\begin{abstract}
"Procurar" tem dois significados diferentes em frases como "procurar alguma coisa no Polo Norte", "procurar a solução de um problema". Uma diferença entre uma expedição de descoberta ao Polo Norte e uma tentativa de encontrar uma solução matemática é que na primeira é possível descrever de antemão o que está sendo procurado, enquanto na matemática quando você descreve a solução você fez a expedição e encontrou o que você procurava. A descrição da prova é a própria prova, enquanto achar a coisa no Polo Norte [não é o suficiente descrevê-la]. Você deve fazer a expedição (WITTGENSTEIN, 2001, p. 7).
\end{abstract}

Mas algum matemático, quando começa a filosofar, ignora que "procurar" tem dois significados diferentes em frases como "procurar alguma coisa no Polo Norte", "procurar a solução de um problema"? Algum matemático, quando começa a filosofar, ignora as diferenças entre uma expedição de descoberta ao Polo Norte e uma tentativa de encontrar uma solução matemática? Ou melhor ainda, como perguntou Piero Sraffa a Wittgenstein em certa ocasião: "Mas alguém realmente já fez esta ou aquela confusão que você ridiculariza?" (MCGUINNESS, 2002, p. 165).

\title{
Considerações finais
}

Este artigo teve por objetivo explicitar algumas das contradições e das inconsistências presentes na filosofia da matemática de Wittgenstein que são pouco discutidas pelos filósofos e pelos matemáticos. $\mathrm{O}$ intuito ao fazê-lo era corroborar as críticas que as ideias matemáticas de Wittgenstein vêm recebendo há décadas, especialmente dos matemáticos, que muitas vezes não poupam palavras para expressar o que pensam de Wittgenstein e de sua obra. Em seu livro sobre Gödel, por exemplo - ele mesmo, como se sabe, um severo antagonista de Wittgenstein -, Rebecca Goldstein relata:

SILVA, Gustavo Augusto Fonseca. Observações sobre a filosofia da matemática de Ludwig Wittgenstein. Griot : Revista de Filosofia, Amargosa/Bahia, v.17, n.1, p.97-113, junho/2018. 
Nenhum matemático com quem falei tem algo de positivo a falar sobre Wittgenstein. Um matemático nitidamente enraivecido que conheço caracterizou a famosa proposição 7 de Wittgenstein, Aquilo de que não podemos falar devemos consignar ao silêncio, como "se realizasse a façanha de ser ao mesmo tempo grandiosa e vazia" (GOLDESTEIN, 2008, p. 100).

Dadas as incoerências do ataque quixotesco de Wittgenstein à matemática pura, não admira que os matemáticos reajam tão mal à sua filosofia. Tampouco admira que o principal livro de Wittgenstein sobre filosofia da matemática, Observações sobre os fundamentos da matemática, tenha sido "o que teve a recepção menos favorável, ao menos pelos lógicos" (AYER, 1985, p. 60). Muito menos admira que Wittgenstein tenha por fim abandonado suas reflexões sobre a filosofia da matemática, em 1944. Nesse ano, conforme Monk (1995, p. 414), John Wisdom escreveu uma breve nota a respeito de Wittgenstein para incluir em um dicionário biográfico e, antes de publicá-la, pediu-lhe que a comentasse. Wittgenstein fez apenas uma modificação, acrescentando uma última sentença ao texto: "A principal contribuição de Wittgenstein foi na filosofia da matemática”. No entanto, ainda de acordo com Monk, dois ou três meses depois, quando Rush Rhees lhe perguntou por seu trabalho em matemática, Wittgenstein lhe respondeu "com um gesto de mão": "Ah, alguém mais pode fazer isso". 


\section{Referências bibliográficas}

AYER, A. J. Ludwig Wittgenstein. Londres: Penguin Books, 1985.

BOUWSMA, O. K. Conversas com Wittgenstein. Lisboa: Relógio D’Água Editores, 2005.

DRURY, M. O’C. Some notes on conversations with Wittgenstein. In: RHEES, Rush (Ed.). Recollections of Wittgenstein: Hermine Wittgenstein; Fania Pascal; F. R. Leavis; John King; M. O'c. Drury. Oxford: Oxford University Press, 1984, p.76-96.

FREGE, Gottlob. Os fundamentos da aritmética. In: FREGE, Gottlob; PEIRCE, Charles Sanders. Escritos coligidos; Sobre a justificação científica de uma conceitografia; Os fundamentos da aritmética. São Paulo: Editora Abril, 1974, p. 203282.

FREGE, Gottlob; PEIRCE, Charles Sanders. Escritos coligidos; Sobre a justificação científica de uma conceitografia; Os fundamentos da aritmética. São Paulo: Editora Abril, 1974.

GLOCK, Hans-Johann. Dicionário Wittgenstein. Rio de Janeiro: Jorge Zahar, 1998.

GOLDSTEIN, Rebecca. Incompletude: a prova e o paradoxo de Kurt Gödel. São Paulo: Companhia das Letras, 2008.

HINTIKKA, M. B.; HINTIKKA, J. Uma investigação sobre Wittgenstein. Campinas: Papirus Editora, 1994.

KUUSELA, Oskari; MCGINN, Marie (Ed.). The Oxford Handbook of Wittgenstein. Oxford: Oxford University Press, 2014.

MCGUINNESS, Brian. Approaches to Wittgenstein: collected papers. Londres; Nova York: Routledge, 2002.

MONK, Ray. Wittgenstein: o dever do gênio. São Paulo: Companhia das Letras, 1995.

POTTER, Michael. Wittgenstein on mathematics. In: KUUSELA, Oskari; MCGINN, Marie (Ed.). The Oxford Handbook of Wittgenstein. Oxford: Oxford University Press, 2014, p. 122-137.

RHEES, Rush (Ed.). Recollections of Wittgenstein: Hermine Wittgenstein; Fania Pascal; F. R. Leavis; John King; M. O'c. Drury. Oxford: Oxford University Press, 1984.

RUSSELL, B. Meu pensamento filosófico. São Paulo: Companhia Editora Nacional, 1960.

Misticismo e lógica e outros ensaios. Rio de Janeiro: Zahar Editores, 1977.

The principles of mathematics. 2. ed. Londres: George Allen and Unwin, 1937.

SANTO AGOSTINHO. A doutrina cristã. 3. ed. São Paulo: Paulus, 2011.

WAISMANN, Friedrich. Introduction to mathematical thinking: the formation of concepts in modern mathematics. Mineola: Dover Publications, 2003.

- Ludwig Wittgenstein y el Cúrculo de Viena. Cidade do México: Fondo de

Cultura Económica, 1973.

WITTGENSTEIN, Ludwig. Cultura e valor. Lisboa: Edições 70, 1992a.

Fichas (Zettel). Lisboa: Edições 70, 1992b.

. Gramática filosófica. São Paulo: Loyola, 2003.

- Investigações filosóficas. São Paulo: Abril Cultural, 1999. (Coleção: Os pensadores).

SILVA, Gustavo Augusto Fonseca. Observações sobre a filosofia da matemática de Ludwig Wittgenstein. Griot : Revista de Filosofia, Amargosa/Bahia, v.17, n.1, p.97-113, junho/2018. 
Observaciones sobre los fundamentos de la matemática. Madri: Alianza Editorial, 1987.

. Observações filosóficas. São Paulo: Loyola, 2005a.

O livro azul. Lisboa: Edições 70, 2008.

. The Big Typescript: TS 213. Oxford: Blackwell Publishing, 2005b.

. Wittgenstein's lectures: Cambridge, 1932-1935. Ambrose, Alice; Macdonald, Margaret (Ed.). Amherst, N.Y.: Prometheus Books, 2001.

. Wittgenstein's lectures on the foundations of mathematics. Cambridge, 1939:

from the notes of R. G. Bosanquet, Norman Malcolm, Rush Rhees, and Yorick Smythies. Diamond, Cora (Ed.). Chicago e Londres: The University of Chicago Press, 1989.

Autor(a) para correspondência: Gustavo Augusto Fonseca Silva, Universidade Federal de Minas Gerais, Faculdade de Filosofia e Ciências Humanas, Avenida Antônio Carlos, 6627 - Pampulha, CEP 31270-901 Belo Horizonte - MG, Brasil.fonsecaugusto@hotmail.com 